\title{
Comparison of Repeated Sprint Ability of Amateur Football Players According to Age and Playing Positions
}

\author{
Ibrahim Can ${ }^{1, *}$ \\ ${ }^{1}$ School of Physical Education and Sport, Gümüşhane University, Gümüşhane, Turkey \\ *Correspondence: School of Physical Education and Sport, Gümüşhane University, Gümüşhane, Turkey. E-mail: \\ ibrahimcan_61_@hotmail.com
}

Received: February 27, 2018

Accepted: March 14, 2018 Online Published: March 30, 2018

doi:10.5430/wje.v8n2p54

URL: https://doi.org/10.5430/wje.v8n2p54

\begin{abstract}
The purpose of this study is to compare the repeated sprint ability of amateur footbal players according to age and playing positions. For this purpose, 174 young amateur soccer players (age: $17.2 \pm 1.8$ years, height: $175.8 \pm 7.5 \mathrm{~cm}$, weight: $67.0 \pm 9.8 \mathrm{~kg}$ ) struggling in different playing positions participated voluntarily to the study. The players divided into six categories as goalkeepers (n: 16 ; age: $17.4 \pm 1.4$ years, height: $181.9 \pm 6.1 \mathrm{~cm}$, weight: $77.4 \pm 9.8 \mathrm{~kg}$ ), central defenders (n: 30 ; age: $16.9 \pm 1.9$ years, height: $179.3 \pm 8.2$ weight: $69.5 \pm 11.2 \mathrm{~kg}$ ), full-backs (n: 34 ; age: $17.3 \pm 1.9$ years, height: $174.9 \pm 5.9 \mathrm{~cm}$, weight: $66.6 \pm 7.8 \mathrm{~kg}$ ), central midfielders (n: 36 ; age: $17.9 \pm 1,6$ years; height: $174.3 \pm 7.1 \mathrm{~cm}$; weight: $67.1 \pm 9.3 \mathrm{~kg}$ ), wide midfielders (n: 30 ; age: $16.8 \pm 1.6$ years, height: $171.5 \pm 5.1 \mathrm{~cm}$, weight: $60.8 \pm 7.4 \mathrm{~kg}$ ) and forwards (n: 28 ; age: $16.6 \pm 1.9$ years, height: $175.9 \pm 8.3 \mathrm{~cm}$, weight: $65.6 \pm 8.0 \mathrm{~kg}$ ). In the study, a repeated sprint test was used to determine the repeated sprint ability of the football players, with an in field 34.2 meter long sprint run and a 25 second rest period after each run. In evaluating the data; descriptive statistics, one-way ANOVA and kruskal-wallis tests were used. According to the analysis results; the best test time (BTT), mean test time (MTT), and total test time (TTT) values in the repeated sprint test showed a statistically significant difference according to playing positions and age factor $(\mathrm{p}<.05)$; On the other hand, fatigue index (FI) value showed a statistically significant difference according to playing positions $(\mathrm{p}<.05)$, but it didn't show any significant difference according to age ( $\mathrm{p}>.05)$. As a result, it can be argued that repeated sprint ability differs according to age and playing positions.
\end{abstract}

Keywords: football, playing position, age, repeated sprint

\section{Introduction}

Football is a team sports involving fluctuations between low and high exercise intensities (Drust et al., 2007) that are required to improve the tactical, technical and physical abilities of players (Helgerud et al., 2001) in a wide playing field, with the participation of many players and determined by the schedules or goals scored by the game rules (Inal, 2004). Because of the duration of a soccer game, according to the heart rate recordings and metabolic measurements of blood and muscle samples obtained during contention, it is clear that the aerobic loading during the competition is very high but that constant anaerobic energy turnover is needed during the periods of the competition (Bangsbo, 1994a; Castagna et al., 2006; Krustrup et al., 2006). While most of the movements made during a soccer game are made without the ball and consist mainly of aerobic exercises (Reilly et al., 2000), most of the activities that make up the most crucial movements of the game (such as sprints, jumps, sudden stops and rapid direction changes) are anaerobic (Al'Hazzaa et al., 2001). For this reason, anaerobic performance, which includes exercises made in explosive form, resulting in a basically short time in a soccer game, plays an important role. That is, according to the intensity of the game, the players have to sprint, enter the ball grabbing battle, run fast or spin. The anaerobic metabolism is active in such cases where the intensity increases. However, when the intensity is sub-maximal and it follows regularly, the aerobic metabolism functions (Stolen et al., 2005). In a study on top-class level Danish soccer, Mohr et al., (2003) reported that activity profile of soccer players in a match as standing $19.5 \%$, walking $41.8 \%$, jogging $16.7 \%$, running $16.8 \%$, sprinting $1.4 \%$, and other $3.7 \%$.

Sprint is a high intensity exercise and a sprint event that takes place in about every 90 seconds and ends on average between 2 and 4 seconds each occurs during a soccer game (Reilly and Thomas, 1976; Bangsbo et al., 1991; Mohr et al., 2003). The need for a sprint during a match is different and athletes must be ready to sprint, recovery and perform it again at the highest possible level (Abrantes et al., 2004). In movement-analysis studies applied in the matchs or 
plays, it is suggested that nearly all the sprints $(\sim 96 \%)$ during the matches were smaller than 30 meters and the majority of them were smaller than 10 meters (Reilly and Thomas, 1976; Bangsbo, 1994a).

In the studies conducted by Spencer et al., $(2004,2006)$, it is stated that sprint runs were repeated without giving enough rest period in soccer games, and therefore, sprint performance which is carried out in consecutively is deteriorated. For this reason, it is one of the most important characteristics of the footbal players that the ability to apply short sprint runnings with short recovery periods (Mujika et al., 2009). Repeated sprint ability was first introduced in the literature by Fitzsimons et al., (1993) and is called as ability to repeat maximal sprint effort regulary (Dawson et al., 1993). The ability to recover from sprints and the renewal of performance for subsequent sprints is an important adjunct to the ability of athletes to perform repeatedly near peak-to-maximal efforts interspersed with short recovery periods (full rest or middle, and low intensity activities) over a wide period of time (Bangsbo et al., 1991; Fitzsimons et al., 1993). Physiologically, repeated sprint ability is a complex skill that is believed to be associated with both neuromuscular (determining maximal sprint speed, such as nerve impulse or motor unit activation) and metabolic $\left(\mathrm{H}^{+}\right.$buffering, oxidative capacity for creatine phosphate regeneration) factors (Glaister, 2005; Spancer et al., 2005). When repeated sprint ability is often associated with a low fatigue index (such as a decrease in the final sprinting performance from the first sprint), a good sprinting ability is better described by a low fatigue index or a high average speed performance without a low fatigue index performance (but a marathon runner with a very low fatigue index will not be classified as having good repetitive sprinting ability) is an important note (Girard et al., 2011).

In a study conducted by Rampinini et al., (2007) on elite professional footbal players, significant correlations between average sprint times in repeated sprint ability test and running distances covered during a match were reported. According to the results of the repeated sprint ability test, performance differences between amateur and professional soccer players were shown (Aziz et al., 2000; Impellizzeri et al., 2008). Because of the concept of today's football game concept, there are some certain studies stating that there is no significant difference between the physical and motoric characteristics of the players who competed in different positions due to the fact that the players approach each other according to their playing positions while they are playing during the match and that the training is specially prepared according to the basic needs of football but it does not include differences specific to footbal players and playing positions (Cerrah et al., 2011; Aslan and Koc, 2015), Gil et al., (2007) reported that, according to their positions, the players showed different physical and motoristic characteristics, and that these differences were compatible with the workload in the field. The aim of this investigation is to compare according to age and play positions of repeated sprint runs applied with short recovery period, which are considered to be an important feature for a successful performance on the football.

\section{Method}

In this study, 174 young amateur soccer players voluntarily participated in different age and playing positions (table 1 and 2). Subjects were divided into 6 categories according to their playing positions: goalkeepers (GK), central defenders (CD), full-backs (FB), central midfielders (CM), wide midfielders (WM) and forwards (F). Participants' health status is good and they do not use a medication that could negatively affect the variables which are being analyzed. Before study, participants and coaches were informed in detail about the purpose of study, the test procedures, the potential risks and benefits of the study, and then the participants signed a written confirmation of their voluntary participation in the study. Participants' height and body weights were obtained using a Seca769 electronic meter (Seca Corporation, Hamburg, Germany) with an accuracy of $0.001 \mathrm{~m}$ and $0.01 \mathrm{~kg}$, respectively. The body weights were measured in the form of kilogram without shoes and only with shorts and t-shirt on the subjects so that they would not affect their weight. Lengths were measured in centimeters, without shoes, body weight evenly distributed over two legs.

Table 1. Descriptive Statistics of Participants According to Playing Positions

\begin{tabular}{lcccc}
\hline Playing Positions & n & Age (years) & Height (cm) & Weight (kg) \\
\hline Goalkeepers (GK) & 16 & $17.4 \pm 1,4$ & $181.9 \pm 6.1$ & $77.4 \pm 9.8$ \\
Central Defenders (CD) & 30 & $16.9 \pm 1.9$ & $179.3 \pm 8.2$ & $69.5 \pm 11.2$ \\
Full-Backs (FB) & 34 & $17.3 \pm 1,9$ & $174.9 \pm 5.9$ & $66.6 \pm 7.8$ \\
Central Midfielders (CM) & 36 & $17.9 \pm 1,6$ & $174.3 \pm 7.1$ & $67.1 \pm 9.3$ \\
Wide Midfielders (WM) & 30 & $16.8 \pm 1,6$ & $171.5 \pm 5.1$ & $60.8 \pm 7.4$ \\
Forwards (F) & 28 & $16.6 \pm 1,9$ & $175.9 \pm 8.3$ & $65.6 \pm 8.0$ \\
Total & 174 & $17.2 \pm 1.8$ & $175.8 \pm 7.5$ & $67.0 \pm 9.8$ \\
\hline
\end{tabular}


Table 2. Descriptive Statistics of Participants According to Age Category

\begin{tabular}{cccc}
\hline Age (years) & $\mathbf{n}$ & Height $\mathbf{( c m})$ & Weight $\mathbf{( k g )}$ \\
\hline 14 & 12 & $163.8 \pm 5.7$ & $52.0 \pm 6.8$ \\
15 & 24 & $173.9 \pm 6.9$ & $58.7 \pm 8.2$ \\
16 & 32 & $174.6 \pm 5.9$ & $67.3 \pm 7.3$ \\
17 & 30 & $179.9 \pm 6.1$ & $69.3 \pm 7.2$ \\
18 & 28 & $175.4 \pm 6.1$ & $69.0 \pm 8.2$ \\
19 & 24 & $179.9 \pm 7.4$ & $71.5 \pm 7.8$ \\
20 & 24 & $176.1 \pm 6.7$ & $72.9 \pm 9.9$ \\
\hline
\end{tabular}

Repeated sprint ability (RSA) of participants were obtained by using a repeated sprint test designed by Bangsbo (1994b), which included 7 sprint applied at maximal speed in a field of 34.2 meters in length and a 25 -second resting period after each running tour (Abrantes et al., 2004). The test area is shown in Figure 1. Before applying the repeated sprint test, participants were given a detailed information about the test procedure. After that, it was applied to low intensity running for 10 minutes and warm-up exercises for 5 minutes and in order to familiarise to test procedure of the participants, short sprints were performed with passive resting. The participants were given full resting time to recover and when they were ready, the repeated sprint test measures were applied two times by giving adequate resting time for obtaining the best results and best results were recorded for statistical analysis. Each sprint value was obtained using a portable photocell (Newtest Powertimer, Model 300s, Oy, Finland) placed at the start and finish points. Fatigue index (FI) values of subjects were calculated according to the following formula (Oliver, 2009).

Formula: \% FI $=(\mathrm{TT}-\mathrm{IT}) / \mathrm{IT} \times 100$

Ideal Time (IT): $\mathrm{S}_{\mathrm{BS}} \times 7$

Total Time (TT): S1 + S2 + S3 + S4 + S5+ S6 + S7

$\mathrm{S}_{\mathrm{BS}}$ : Best Score (Time)

S: Sprint

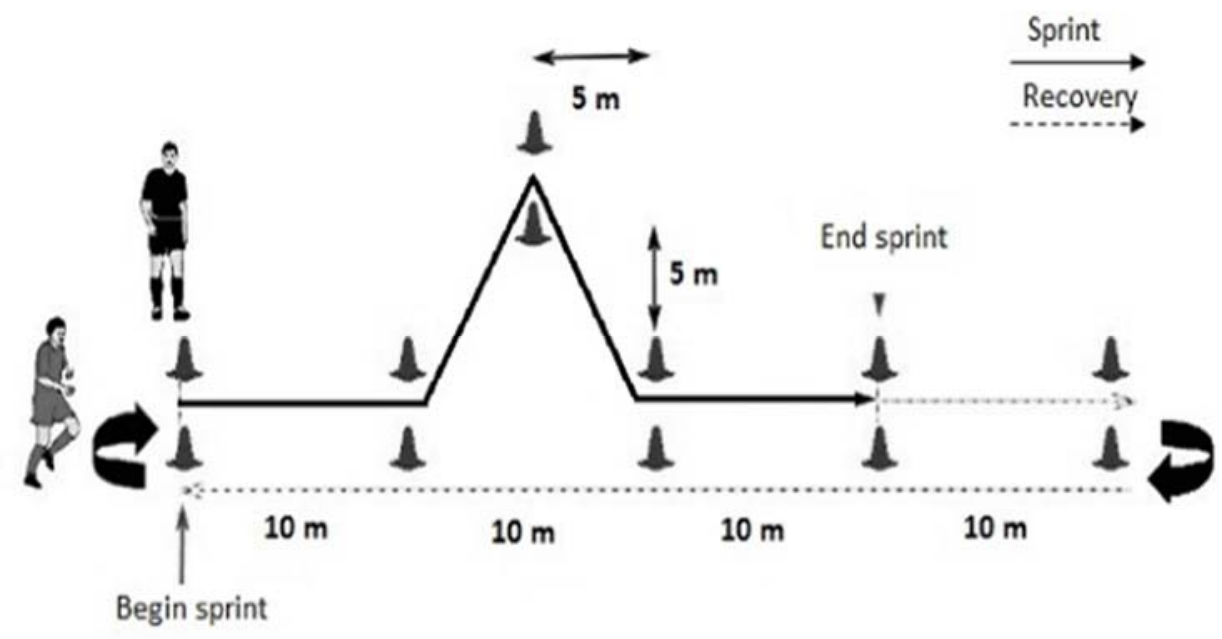

Figure 1. Repeated Sprint Test Field (Sporis et al., 2012)

\section{Statistical Analysis}

Data obtained from the investigation was presented as descriptive statistics. The normality of data distribution according to playing positions and age categories was examined by using Kolmogorov Smirnov test and parametric analysis technique was used for the data with normal distribution, while nonparametric analysis technique was used for the parameters having no normal distribution. One-way analysis of variance (ANOVA) was used to determine difference according to playing position and age categories of the best test time, mean test time and total test time 
parameters in the repeated sprint test of research group. On the other hand, when the difference according to playing positions of the fatigue index values, one of the parameters in the repeated sprint test, were obtained by one-way ANOVA; the difference according to age categories were analyzed by the Kruskal-Wallis test. Scheffe and Dunnett tests were applied for multiple comparisons between groups. The SPSS 16.0 statistical package program (SPSS Inc., Chicago, USA) was used for all analyzes. The statistical significance level was accepted as $p<.05$ in all analyzes.

\section{Results}

Descriptive statistical values showing repeated sprint test performances according to participant's playing positions are given in table 3.According to the results of one-way variance analysis (ANOVA) applied to determine whether running performance in the repeated sprint test differentiate according to the playing positions or not, there are a statistically significant different according to playing positions in terms of BTT (table 4), MTT (table 5), TTT (table 6) and YI (table 7) values in the repeated sprint test of soccer players competed in different playing positions $(\mathrm{p}<.05)$. According to the results of the Scheffe multiple comparison test for the purpose of determine differences between groups, it is concluded that there is a statistically significant difference between only CD and FB players in terms of the BTT values (table 4); between only GK and FB players in terms of MTT (table 5) and TTT values (table 6); and between CD, FB and CM positions with GK in terms of FI values in the repeated sprint test ( $<.05$; table 7$)$. There is no a statistically significant difference between the other playing positions ( $p>.05)$.

Table 3. Repeated Sprint Parameters of Participants According to Playing Positions

\begin{tabular}{lccccc}
\hline Playing Positions & n & BTT (sec) & MTT (sec) & TTT (sec) & FI (\%) \\
\hline Goalkeepers & 16 & $7.09 \pm 0.21$ & $7.53 \pm 0.15$ & $52.67 \pm 1.03$ & $6.18 \pm 2.21$ \\
Central Defenders & 30 & $7.13 \pm 0.25$ & $7.43 \pm 0.28$ & $52.01 \pm 1.95$ & $4.16 \pm 1.51$ \\
Full-Backs & 34 & $6.89 \pm 0.32$ & $7.21 \pm 0.32$ & $50.46 \pm 2.25$ & $4.48 \pm 1.39$ \\
Central Midfielders & 36 & $7.03 \pm 0.22$ & $7.32 \pm 0.30$ & $51.25 \pm 2.10$ & $4.16 \pm 1.79$ \\
Wide Midfielders & 30 & $6.94 \pm 0.28$ & $7.28 \pm 0.31$ & $50.96 \pm 2.19$ & $4.92 \pm 1.53$ \\
Forwards & 28 & $7.03 \pm 0.26$ & $7.34 \pm 0.26$ & $51.41 \pm 1.84$ & $4.52 \pm 1.69$ \\
\hline Total & 174 & $7.01 \pm 0.27$ & $7.33 \pm 0.29$ & $51.33 \pm 2.09$ & $4.59 \pm 1.73$ \\
\hline
\end{tabular}

BTT: Best Test Time, MTT: Mean Test Time, TTT: Total Test Time, FI: Fatigue Index

Table 4. Results of one-way variance Analysis (ANOVA) related to the differences of Participants' Best Test Time Values in the Repeated Sprint Test According to the Playing Positions

\begin{tabular}{lccccc}
\hline Playing Positions & $\mathbf{x}$ & sd & F & p & Difference \\
\hline Goalkeepers & 7.09 & 0.21 & & & \\
Central Defenders & 7.13 & 0.25 & & & \\
Full-Backs & 6.89 & 0.32 & 3.325 & $0.007^{*}$ & CD - FB \\
Central Midfielders & 7.03 & 0.22 & & & \\
Wide Midfielders & 6.94 & 0.28 & & & \\
Forwards & 7.01 & 0.27 & & & \\
\hline$*$ & & &
\end{tabular}

Table 5. Results of One-Way Variance Analysis (ANOVA) Related to the Differences of Participants' Mean Test Time Values in the Repeated Sprint Test According to the Playing Positions

\begin{tabular}{lccccc}
\hline Playing Positions & $\mathbf{x}$ & ss & F & p & Difference \\
\hline Goalkeepers & 7.53 & 0.15 & & & \\
Central Defenders & 7.43 & 0.28 & & & \\
Full-Backs & 7.21 & 0.32 & 3.632 & $0.004^{*}$ & GK - FB \\
Central Midfielders & 7.32 & 0.30 & & & \\
Wide Midfielders & 7.28 & 0.31 & & & \\
\hline Forwards & 7.34 & 0.26 & & &
\end{tabular}

${ }^{*} \mathrm{p}<.05 ;$ GK: Goalkeepers, FB: Full-Backs 
Table 6. Results of One-Way Variance Analysis (ANOVA) Related to the Differences of Participants' Total Test Time Values in the Repeated Sprint Test According to the Playing Positions

\begin{tabular}{lccccc}
\hline Playing Positions & $\mathbf{x}$ & sd & F & p & Difference \\
\hline Goalkeepers & 52.67 & 1.03 & & & \\
Central Defenders & 52.01 & 1.95 & & & \\
Full-Backs & 50.46 & 2.25 & 3.603 & $0.004^{*}$ & GK - FB \\
Central Midfielders & 51.25 & 2.10 & & & \\
Wide Midfielders & 50.96 & 2.19 & & & \\
Forwards & 51.41 & 1.84 & & & \\
\hline
\end{tabular}

$* \mathrm{p}<.05 ;$ GK: Goalkeepers, FB: Full-Backs

Table 7. Results of One-Way Variance Analysis (ANOVA) Related to the Differences of Participants' Fatigue Index Values in the Repeated Sprint Test According to the Playing Positions

\begin{tabular}{lccccc}
\hline Playing Positions & $\mathbf{x}$ & sd & F & p & Difference \\
\hline Goalkeepers & 6.18 & 2.21 & & & \\
Central Defenders & 4.16 & 1.51 & & & GK - CD \\
Full-Backs & 4.48 & 1.39 & 4.116 & $0.001^{*}$ & GK - FB \\
Central Midfielders & 4.16 & 1.79 & & & GK - CM \\
Wide Midfielders & 4.92 & 1.53 & & & \\
Forwards & 4.52 & 1.69 & & \\
\hline GK: Goalkeepers, CD: Central defenders, FB: Full-Backs, CM: Central Midfielders &
\end{tabular}

Table 8. Repeated Sprint Parameters of Participants According to Age Categories

\begin{tabular}{lccccc}
\hline Age (years) & n & BTT (sec) & MTT (sec) & TTT (sec) & FI (\%) \\
\hline 14 & 12 & $7.22 \pm 0.13$ & $7.53 \pm 0.23$ & $52.72 \pm 1.60$ & $4.30 \pm 1.79$ \\
15 & 24 & $7.21 \pm 0.31$ & $7.55 \pm 0.25$ & $52.85 \pm 1.74$ & $4.77 \pm 1.31$ \\
16 & 32 & $7.10 \pm 0.22$ & $7.43 \pm 0.27$ & $52.03 \pm 1.91$ & $4.65 \pm 1.42$ \\
17 & 30 & $6.93 \pm 0.19$ & $7.27 \pm 0.22$ & $50.88 \pm 1.58$ & $4.82 \pm 2.14$ \\
18 & 28 & $6.82 \pm 0.23$ & $7.14 \pm 0.25$ & $50.00 \pm 1.76$ & $4.68 \pm 1.93$ \\
19 & 24 & $6.85 \pm 0.19$ & $7.11 \pm 0.15$ & $49.77 \pm 1.07$ & $3.78 \pm 1.32$ \\
20 & 24 & $7.06 \pm 0.30$ & $7.41 \pm 0.36$ & $51.86 \pm 2.50$ & $4.94 \pm 1.92$ \\
Total & 174 & $7.01 \pm 0.27$ & $7.33 \pm 0.29$ & $51.33 \pm 2.09$ & $4.59 \pm 1.73$ \\
\hline
\end{tabular}

BTT: Best Test Time, MTT: Mean Test Time, TTT: Total Test Time, FI: Fatigue Index

Table 9. Results of One-Way Variance Analysis (ANOVA) Related to the Differences of Participants' Best Test Time Values in the Repeated Sprint Test According to the Age Categories

\begin{tabular}{lcccccc}
\hline Age (years) & $\mathbf{n}$ & $\mathbf{x}$ & sd & $\mathbf{F}$ & $\mathbf{p}$ & Difference \\
\hline 14 & 12 & 7.22 & 0.13 & & & \\
15 & 24 & 7.21 & 0.31 & & & \\
16 & 32 & 7.10 & 0.22 & & & $14-15>17-18-19$ \\
17 & 30 & 6.93 & 0.19 & 10.512 & $0.000^{*}$ & $16>18-19$ \\
18 & 28 & 6.82 & 0.23 & & & \\
19 & 24 & 6.85 & 0.19 & & & \\
20 & 24 & 7.06 & 0.30 & & & \\
Total & 174 & 7.01 & 0.27 & & & \\
\hline
\end{tabular}


Table 10. Results of One-Way Variance Analysis (ANOVA) Related to the Differences of Participants' Mean Test Time Values in the Repeated Sprint Test According to the Age Categories

\begin{tabular}{lcccccc}
\hline Age (years) & $\mathbf{n}$ & $\mathbf{x}$ & sd & $\mathbf{F}$ & $\mathbf{p}$ & Difference \\
\hline 14 & 12 & 7.53 & 0.23 & & & \\
15 & 24 & 7.55 & 0.25 & & & \\
16 & 32 & 7.43 & 0.27 & & & $14>18-19$ \\
17 & 30 & 7.27 & 0.22 & 11.076 & $0.000^{*}$ & $15>17-18-19$ \\
18 & 28 & 7.14 & 0.25 & & & $16>18-19$ \\
19 & 24 & 7.11 & 0.15 & & & $20>19$ \\
20 & 24 & 7.41 & 0.36 & & & \\
Total & 174 & 7.33 & 0.29 & & & \\
${ }^{* p}<.05$ & & & & & &
\end{tabular}

Table 11. Results of One-Way Variance Analysis (ANOVA) Related to the Differences of Participants' Total Test Time Values in the Repeated Sprint Test According to the Age Categories

\begin{tabular}{lcccccc}
\hline Age (years) & $\mathbf{n}$ & $\mathbf{x}$ & sd & $\mathbf{F}$ & $\mathbf{p}$ & Difference \\
\hline 14 & 12 & 52.72 & 1.60 & & & \\
15 & 24 & 52.85 & 1.74 & & & \\
16 & 32 & 52.03 & 1.91 & & & $14>18-19$ \\
17 & 30 & 50.88 & 1.58 & 11.136 & $0.000^{*}$ & $15>17-18-19$ \\
18 & 28 & 50.00 & 1.76 & & & $16>18-19$ \\
19 & 24 & 49.77 & 1.07 & & & $20>19$ \\
20 & 24 & 51.86 & 2.50 & & & \\
Total & 174 & 51.33 & 2.09 & & & \\
$*_{\mathrm{p}<.05}$ & & & & & &
\end{tabular}

Table 12. Results of Kruskal-Wallis Test Related to the Differences of Participants' Fatigue Index Values in the Repeated Sprint Test According to the Age Categories

\begin{tabular}{lcccccc}
\hline Age (years) & $\mathbf{n}$ & $\mathbf{x}$ & sd & Mean Rank & $\mathbf{x}^{2}$ & $\mathbf{p}$ \\
\hline 14 & 12 & 4.30 & 1.79 & 77.17 & & \\
15 & 24 & 4.77 & 1.31 & 94.33 & & \\
16 & 32 & 4.65 & 1.42 & 93.19 & & \\
17 & 30 & 4.82 & 2.14 & 90.77 & 6.173 & 0.404 \\
18 & 28 & 4.68 & 1.93 & 89.07 & & \\
19 & 24 & 3.78 & 1.32 & 66.17 & & \\
20 & 24 & 4.94 & 1.92 & 93.67 & & \\
Total & 174 & 4.59 & 1.73 & & & \\
\hline
\end{tabular}

A statistically significant difference was found between the groups when the analysis results of the difference of the BTT $(p<.05$; table 9), MTT $(p<.05$; table 10) and TTT $(p<.05$; table 11$)$ values in the RSA according to the age categories were examined. According to the Dunnett multiple comparison test results for BTT, there was a significant difference between players in the 14 and 15 age categories with players in the 17, 18, and 19 age categories. It was determined that players in the 18 and 19 age categories have statistically better running values than the players in the 16 age category. For MTT, it was obtained that players in the 18 and 19 age categories have statistically better values than the players in the 14,15 and 16 age categories $(\mathrm{p}<.05)$. In addition, the players in the 17 age category have better MTT values than the players in the 15 age category just as the players in the 19 age category have better MTT values than the players in the 20 age category $(\mathrm{p}<.05)$. Apart from these, there is no statistically significant difference between the other age categories ( $\mathrm{p}>.05)$.

According to Dunnett's multiple comparison results to determine the differences between the age categories, it was 
determined that the TTT values in repeated sprint test of the players in 18 and 19 age categories were better players in the 14,15 and 16 age categories $(p<.05)$. On the other hand, it was obtained that players in the 17 age category have better TTT values at a significant level than players in the 15 age category just as the players in the 19 age category have better TTT values at the significant level than players in the 20 age category $(\mathrm{p}<.05)$. Apart from these, there is no statistically significant difference between the other age categories ( $p>.05)$.

According to the results of the kruskal wallis given in table 12, there is no significant difference in terms of fatigue index values of the players between age categories $(\mathrm{p}>.05)$. In other words, fatigue index values of players in different age categories are similar.

\section{Discussion}

Nowadays, the ability to apply short sprint runs with short recovery periods is one of the most important characteristics of soccer players (Mujika et al., 2009). In football matches, players are spoiled by sprinting repeatedly without being given enough time to rest (Spencer et al. 2004, 2006). The aim of this study is to compare the repeated sprint test performances of young amateur soccer players in different age categories and playing positions. The findings of the study show that the best time time, mean test time and total test time values in the repeated sprint test showed statistically significant differences according to playing positions and age factor $(\mathrm{p}<.05)$; On the other hand, the fatigue index value shows a statistically significant difference according to the playing positions $(p<.05)$, but does not show any significant difference according to the age factor ( $\mathrm{p}>.05)$.

Looking at the studies in literature comparing the repeated sprint performance of football players by the age factor, in a study conducted by Ceylan et al., (2016) on young amateur football players with two years of training experience at least in which $6 \times 35$ meter repeated sprint test was used, it has been observed that the running time of young football players playing in the categories of U15, U17 and U19 in repeated sprint test has differentiated. In the relevant study, it has been determined that the football players in U15 category have the worst values in terms of the BTT and MTT values in repeated sprint test. In contrast, no statistically significant difference has been obtained between the groups of U17 and U19. In a study of Özdemir et al., (2014) conducted on young football players of a football club playing in U14, U15 and U16 age categories in Spor Toto Super League, both 12x20 meter repeated sprint test with a resting period of 20 second and 6x40 meter repeated sprint test with a resting period of 30 second were applied. In the above-mentioned study, it has been established that there is a statistically significant difference between groups in terms of the BTT and TTT values obtained from the both of repeated sprint tests. It has also been ascertained that the young football players in U14 age group are slower than the young football players of U14 age group in terms of the BTT in $12 \times 20$ meter repeated sprint test but they are slower than the young football players of U15 and U16 age groups in terms of TTT. It has been determined that the young football players in U14 age group are slower than the young football players of U15 and U16 age groups in terms of the BTT in $6 \times 40$ meter repeated sprint test and they are slower than the young football players of U15 age group in terms of TTT. Moreover, it has been stated that there is no statistically significant difference between the groups in terms of the performance decline percentages in both of the repeated sprint test.

In a study of Mujika et al., (2009) in which $6 \times 30$ meter repeated sprint test with a resting period of 30 second was applied in order to determine the repeated sprint ability of young football players in different age groups (U11, U12, U13, U14, U15, U16, U17, U18, U19) playing in development leagues of a professional football club, U11 and U12 groups have been slower than all other age groups although there is no significant difference between U11 $(33.15 \pm 1.84 \mathrm{sec})$ and $\mathrm{U} 12(32.18 \pm 1.26 \mathrm{sec})$ in terms of total test time. TTT values of U13 group $(30.88 \pm 1.73 \mathrm{sec})$ is faster than U11 and U12 age groups and slower than U14 and U18 age groups; however, it is significantly different than all other groups. Similarly, TTT values of U14 $(28.65 \pm, 58 \mathrm{sec})$ age group is faster than U11, U12 and U13 groups and slower than U15 and U18 age groups; however, it is significantly different than all other groups. In terms of TTT, there is no statistically significant difference between the age groups of U15 (27.25, $82 \mathrm{sec})$, U16 $(26.76 \pm, 73 \mathrm{sec}), \mathrm{U} 17(26.61 \pm, 53 \mathrm{sec})$ and U18 $(26.34 \pm, 94 \mathrm{sec})$. Although there is a statistically significant difference between groups of U11 and U15 in TTT values, it is observed that no statistically significant difference exists between groups in terms of TTT after U15 age. It has been determined that there is no difference between age groups in terms of performance decline percentage. There is also no significant difference between U15 and U18 age groups in terms of the recorded time for each of the six (6) sprints. However, a significant difference has been obtained only in one sprint time between U11 and U14 age groups. The reason for the absence of a significant difference between groups after the age of 15 can be the factors that reveal the development of repeated sprint ability such as faster phosphocreatine resynthesis of training, more oxidative capacity and better acid-base balance (Ratel et al., 2006) and 
it has been suggested that fatigue resistance during repeated sprint exercise can balance the age-depended deterioration (Mendez-Villanueva et al., 2011).

In a study of Mendez-Villanueva et al., (2011) comparing the performance of young football players competing in different age categories (U14, U16 and U18) in 10x30 meter repeated sprint test applied with a resting period of 25 seconds, it has been determined that there is a statistically significant difference between groups in terms of the MTT values in repeated sprint test. In the relevant study, MTT is $5.04( \pm, 28 \mathrm{sec})$ for U14 age group, $4.62( \pm, 17 \mathrm{sec})$ for U16 age group and $4.39( \pm, 12 \mathrm{sec})$ for U18 age group. As can be understood from the results, the best mean sprint time has been reached in U18 age group and the worst mean sprint time is in U14 age group. Similarly, it has been uttered that the ability of repeating the short-term maximum efforts reduces by age (Ratel et al., 2006). Abrantes et al., (2004) have hypothesized that there is a visible decline in MTT $(7.83 \pm, 07,6.86 \pm, 06$ and $6.35 \pm, 07 \mathrm{sec}$, respectively) of Portuguese football players in different age groups in repeated sprint test by age and this information can be transformed into valuable knowledge in ability determination, conformity assessment and planning.

In a study of Dellal and Wong (2013) conducted on the 10x20 meter repeated sprint test performance of young football players competing in different age groups (U15, U17 and U19) of France $1^{\text {st }}$ League football club with 20 seconds of active recovery, the best test time, mean test time and total test time values of young football players during the test are $3.29( \pm, 06 \mathrm{sec}), 3.34( \pm, 06 \mathrm{sec})$ and $20.05( \pm, 38 \mathrm{sec})$ for U15 football players; $3.14( \pm, 08 \mathrm{sec}), 3.19$ $( \pm 0.09 \mathrm{sec})$ and $18.23( \pm 0.52 \mathrm{sec})$ for U17 football players and $3.01( \pm, 10 \mathrm{sec}), 3.04( \pm, 10 \mathrm{sec})$ and $18.23( \pm, 60 \mathrm{sec})$ for U19 football players. In the relevant study, it has been ascertained that the repeated sprint ability is affected from the age factor (especially between the ages of 15 and 19) and the BTT, MTT and TTT values during the test reduce with age. Wong et al., (2012) have expressed that the sprint ability is affected from different motor abilities and there can be similar differences related to the performance in repeated sprint ability. In other words, it has been stated that repeated sprint ability depends on the skills level of players. In fact, it has been found in the studies of Impellizzeri et al., (2008) and Rampinini et al., (2009) that the Professional football players exhibit better performance than the amateur football players in repeated sprint test. This can explain the differences between the game performance the fatigue level of amateur and professional football players according to the different game levels. In this regard, trainers should be careful about physiological profiles, morphology, anthropometric characteristics, chronological age, game level, biological maturity and age of training in order to be able to determine which factors can affect the repeated sprint ability of young football players (Lago-Penas et al., 2011; Wong et al., 2012).

In a study conducted by Aziz et al, (2008), it was obtained that both TTT $(26.00 \pm, 91 \mathrm{sec})$ and BTT $(3.12 \pm, 09 \mathrm{sec})$ values in the repeated sprint test of the goalkeepers were lower than those in the other playing positions $(\mathrm{p}<.05)$. In the mentioned study,TTT and BTT values in the repeated sprint test were obtained as $25.47( \pm, 91 \mathrm{sec}) \& 3.08( \pm, 11 \mathrm{sec})$ for central defender players, $25.55( \pm, 83 \mathrm{sec}) \& 3.09( \pm, 11 \mathrm{sec})$ for central midfield players, $24.89( \pm, 87 \mathrm{sec}) \& 3.01$ $( \pm, 10 \mathrm{sec})$ for forward players, respectively. Soccer players competing in the forward area have statistically better TTT and BTT values than central defender and central midfielder soccer players $(\mathrm{p}<.05)$. Kaplan (2010) found that there was no a statistically significant difference between BTT, MTT and YI values in repeated sprint test of amateur soccer players competing in different playing positions (goalkeeper, defender, midfield and forward). In the mentioned study, repeated sprint distance applied to football players is 34.2 meters and BTT values for this distance was obtained as 7.49 $( \pm, 29 \mathrm{sec})$ for goalkeepers, $7.37( \pm, 19 \mathrm{sec})$ for defenders, $7.35( \pm, 27 \mathrm{sec})$ for midfielders and $7.32( \pm, 32 \mathrm{sec})$ for forwards. The MTT values in repeated sprint test were obtained as $7.72( \pm, 27 \mathrm{sec})$ for goalkeepers, $7.57( \pm, 20 \mathrm{sec})$ for defenders, $7.59( \pm, 23 \mathrm{sec})$ for midfielders and $7.51( \pm, 33 \mathrm{sec})$ for forwards. In a study conducted by Impellizzeri et al., (2008) it has been found that repeated sprint test performance does not statistically differentiate according to playing positions (defender, full-back, midfield and forward) but defender players have lower repeated sprint performance when compared to players competing in other playing positions.

In a study on U19 football players by Brahim et al., (2016) in order to compare repeated sprint ability according to the players' playing positions, 3 repeated sprint tests including $7 \times 34.2 \mathrm{~m}$ repeated sprint test, $12 \times 20$ meter repeated sprint test and 6x40 meter repeated sprint test were applied. The TTT, BTT and FI values of the players in $7 \times 34.2$ meter repeated sprint test were obtained as $49.66( \pm 1,97 \mathrm{sec}), 6.78( \pm, 26 \mathrm{sec}), 4.67( \pm 4.00 \%)$ for midfielders, $49.90( \pm 3,22$ sec), 6.93 (, $\pm 38 \mathrm{sec}), 2.86( \pm 1.42 \%)$ for defenders and 48.48 ( $\pm 3,12 \mathrm{sec}), 6.53$ (, $\pm 36 \mathrm{sec}), 6.12( \pm 4.14 \%)$ for forwards, respectively. Looking at the TTT obtained during the test, it is observed that the differences between the game positions are considerably insignificant. However, it is observed regarding the fastest test time during the test that forwards have a better running time when compared to the central midfielders and central defender players. Compared to the central defenders, it is observed that forwards have more fatigue index percentage. Total test time, the fastest time and fatigue index values of players in $12 \times 20$ meter repeated sprint test have been found as $( \pm 2.46 \mathrm{sec}), 5.35( \pm, 22$ sec), $3.71( \pm 2.97 \%)$ for central midfielders; 66.28 ( $\pm 2.36 \mathrm{sec}), 5.32( \pm, 22 \mathrm{sec}), 3.78( \pm 1.92 \%)$ for central defenders 
and $67.90( \pm, 60 \mathrm{sec}), 5.45( \pm, 13 \mathrm{sec}), 3.78( \pm 2.20 \%)$ for forwards. Concerning the TTT values obtained during the test, it is observed that there are huge difefrences between the positions and the best test performance is displayed by central defenders. Looking at the fastest running time during the test, it is observed that there is a moderate difference between the positions and central defenders have a better running time when compared to the central midfielders and forwards. The percentage of fatigue index (decline in speed) between the positions is insignificant. Finally, total test time, the fastest test time and fatigue index values of players in $6 \times 40$ meter repeated sprint test have been found to be 35.77 (, \pm 77 $\mathrm{sec}), 5.80$ (, $\pm 13 \mathrm{sec}), 2.87$ ( $\pm 1.19 \%)$ for central midfielders; 36.18 (, $\pm 96 \mathrm{sec}), 5.90$ (, $\pm 16 \mathrm{sec}), 2.32( \pm 1.06 \%)$ for central defenders and $36.67( \pm 1.32 \mathrm{sec}), 5.92( \pm, 14 \mathrm{sec}), 3.14( \pm 1.89 \%)$ for forwards, respectively. When the TTT values obtained during the test is analyzed, it is observed that there are huge differences between the positions and the best test performance is displayed by central defenders. In terms of the BTT and TTT values during the test, it has been determined that there is a huge difference between the central midfielders and forwards and the central midfielders have a better value than the forwards in the parameters of both TTT and BTT values. The difference between central midfielders and central defenders is at moderate level. Moreover, it is observed that forwards have higher fatigue index percentage than the central midfielders.

In the studies conducted on young football players playing in youth setup of a football team in Turkish Super League (Can et al., 2012) and the football players playing in Turkish Super League (Hazir et al., 2002), it has been determined that there is no statistically significant difference between the 10 meters and 30 meters sprint times of football players competing in different positions. In the studies of Gil et al., (2007) and Malina et al., (2005), it has been revealed that there is no statistically significant difference between the sprint times of football players competing in different positions; however, the forwards are faster than the central midfielders, goalkeepers and central defenders in 30 meter sprint test. In the study of Melina et al., (2004) conducted on young football players in the age group of 14 and the study of Lago-Penas et al., (2011) conducted on young football players with an average age of 15.5, it has been determined that there isn't any statistically significant difference between 30 meter sprint time and game positions.

In a study of Wong et al., (2009), 10 meter and 30 meter sprint times of football players in Hong Kong U14 age category have been compared by their positions and 10 meter sprint times of goalkeepers, central defenders, central midfielders and forwards have been found as $2.06( \pm, 12 \mathrm{sec}), 2.09( \pm, 23 \mathrm{sec}), 2.05( \pm, 14 \mathrm{sec})$ and $2.07( \pm, 15 \mathrm{sec})$ respectively while their 30 meter sprint times have been determined as $4.92( \pm .32 \mathrm{sec}), 4.81( \pm .36 \mathrm{sec}), 4.82( \pm 31 \mathrm{sec})$ and $4.96( \pm .40 \mathrm{sec})$ respectively. It has been ascertained that central midfielders have the shortest mean running time in 10 meter sprint test and central defenders have the worst mean running time while it has been indicated that central defenders have the shortest mean running time in 30 meter sprint test and the worst mean running time belongs to forwards. It has also been established that both 10 meter and 30 meter sprint times of players don't differ significantly by the positions.

Taşkın (2008) has examined the 30 meter sprint times of football players competing in different categories in Turkey according to the positions and found that there isn't any statistically significant difference between sprint times of football players by the positions. In this study, 30 meter sprint times of goalkeepers, central defenders, central midfielders and forwards have been found as $4.26( \pm, 13 \mathrm{sec}), 4.21( \pm, 18 \mathrm{sec}), 4.22( \pm, 16 \mathrm{sec})$ and $4.21( \pm, 13 \mathrm{sec})$. In the study of Franks et al., (1999), 15 meter sprint times of British football players by their positions have been compared and the MTT values have been found to be $2.62( \pm, 07 \mathrm{sec})$ for goalkeepers, $2.48( \pm, 04 \mathrm{sec})$ for central defenders, 2.51 $( \pm, 04 \mathrm{sec})$ for central midfielders and $2.43( \pm, 07 \mathrm{sec})$ for forwards. Moreover, 40 meter sprint times of players are as follows; $5.83( \pm, 11 \mathrm{sec})$ for goalkeepers, $5.53( \pm, 06 \mathrm{sec})$ for central defenders, $5.59( \pm, 06 \mathrm{sec})$ for central midfielders and $5.43( \pm, 11 \mathrm{sec})$ for forwards. In the study of Reilly and Wells (1999), 30 meter sprint times of football players competing in different positions have been analyzed and found as $4.81( \pm, 18 \mathrm{sec})$ for central defenders, $4.86( \pm, 19 \mathrm{sec})$ for full-backs, $4.84( \pm, 17 \mathrm{sec})$ for central midfielders and $4.80( \pm, 25 \mathrm{sec})$ for forwards. As can be understood from the results, there isn't any statistically significant difference found between the positions although forward players have the fastest running time in 30 meter sprint test. In the study of Silvestre et al., (2006), 36.5 meter sprint values of football players have been examined by their positions in the match and found as 5.3 (, $\pm 1 \mathrm{sec})$ for goalkeepers, $4.9( \pm, 2$ $\mathrm{sec})$ for central defenders, $5.0( \pm, 2 \mathrm{sec})$ for central midfielders and $4.9( \pm, 2 \mathrm{sec})$ for forwards.

It has been determined that BTT, MTT and TTT values in repeated sprint test exhibits a statistically significant difference by the positions and age factor; however, FI values displays a significant difference by the positions while it doesn't differ by the age factor. A significant difference has been found only between central defenders and full-backs in terms of the BTT values in repeated sprint test; only between goalkeepers and full-backs in terms of MTT and TTT values; between goalkeepers and central defenders, full-backs and central midfielders in terms of FI values. Apart from that, there isn't any statistically significant difference between other positions. Goalkeepers often perform extremely high explosive movements such as jumping, hopping and catching together with forward, 
backward and sideway burst movements in order to keep the goals and to obtain the most appropriate defensive position. These activities are carried out intermittently within the penalty area and they rarely do all-out running movements such as going out of the penalty area in order to narrow shooting of rival forward player in individual positions or to block the through balls. For this reason, general activity profiles are defined as multiple agility instead of multiple sprints (Whall, 2001). This indicates that repeated sprint isn't a highly important physical fitness for goalkeepers due to their position during the matches. In conclusion, it can be suggested that repeated sprint ability differs by age and positions.

\section{References}

Abrantes, C., Maças, V., \& Sampaio, J. (2004). Variation in football players's sprint test performance across different ages and levels competition. Journal of Sports Science and Medicine, 3(1), 44-49.

Al'Hazzaa, MH., Almuzaini, SK., Al-Rafaee, AS., Sulaiman, MA., Dafterdar, YM., Al-Ghamedi, A., \& Al-Khuraiji, NK. (2001). Aerobic and anaerobic power characteristic of Saudi elite soccer players. The Journal of Sports Medicine and Physical Fitness, 41(1), 54-61.

Aslan, CS., \& Koç, H. (2015). Comparing selected physical and motoric characteristics of Turkish amateur soccer players according to paying positions. CBU Journal of Physical Education and Sport Sciences, 10(1), 56-65.

Aziz, AR., Chia, M., \& Teh, KC. (2000). The relationship between maximal oxygen uptake and repeated sprint performance indices in field hockey and soccer players. The Journal of Sports Medicine and Physical Fitness, 40(3), 195-200.

Bangsbo, J. (1994a). The physiology of soccer with special reference to intense intermittent exercise. Acta Physiologica Scandinavica, 619, 1-155.

Bangsbo, J. (1994b). Fitness training for football: A scientific approach. Bagsverd. HO+Storm.

Bangsbo, J., Norregaard, L., \& Thorsoe, F. (1991). Activity profile of competition soccer. Canadian Journal of Sport Science, 16(2), 110-116.

Brahim, M.B., Mohamed, A., Shaher, A., \& Shalfawi, I. (2016). The evaluation of soccer players performance on different repeated sprint times: Training and testing implications. Kinesiologia Slovenica, 22(2), 49-63.

Can, I., Cihan, H., Imamoğlu, R., \& Aka, S.K. (2012). The comparison according to playing positions of $10 \mathrm{~m}$ and 30 m sprint times in young football players. Journal of Sports Science and Health, 3(2), 113-121.

Castagna, C., Impellizeri, MF., Chamari, K. Carlomango, D., \& Rampinini, E. (2006). Aerobic fitness and Yo-Yo continuous and intermittent tests performances in soccer players: a corelation study. Journal of Strength and Conditioning Research, 20(2), 320-325. https://doi.org/10.1519/00124278-200605000-00015

Cerrah, AO., Polat, C., \& Ertan, H. (2011). Evaluating some physical technique characteristics of süper amateur soccer players according to their playing positions. Nigde University Journal of Physical Education And Sport Sciences, $5(1), 1-6$.

Ceylan, L., Demirkan, E., \& Küçük, H. (2016). Examination of sprint duration and repeated sSprint level of soccer players in different age group. International Journal of Science Culture and Sport, 4(SI 1), 188-199. https://doi.org/10.14486/IntJSCS548

Dawson, B., Ackland, T., \& Ward, D. (1993). The relationship of repeated sprint ability to aerobic power and performance measures of anaerobic work capacity and power. Australian Journal of Science and Medicine in Sport, 25(4), 88-93.

Dellal, A., \& Wong, DP. (2013). Repeated sprint and change of direction abilities in soccer players: Effects of age group. Journal of Strength and Conditioning Research, 27(9), 2504-2508. https://doi.org/10.1519/JSC.0b013e31827f540c

Drust, B., Atkinson, G., \& Reilly, T. (2007). Future perspectives in the evaluation of the physilogical of soccer. Sports Medicine, 37(9), 793-805. https://doi.org/10.2165/00007256-200737090-00003

Fitzsimons, M., Dawson, B, Ward, D., \& Wilkinson, A. (1993). Cycling and running tests of repeated sprint ability. Australian Journal of Science and Medicine Sport, 25, 82-87.

Franks, AM., Williams, AM., Reilly, T., \& Nevill, A. (1999). Talent identification in elite youth soccer players: Physical and physiological characteristics. Communication to the Fourth World Congress on Science and 
Football, Syndey. Journal of Sports Sciences, 17(10), 812.

Gil, SM., Gil, J., Ruiz, F., Irazusta, A., \& Irazusta, J. (2007). Physiological and anthropometric characteristics of young soccer players according to their playing position: Relevance for the selection process. Journal of Strength and Conditioning Research, 21(2), 438-445. https://doi.org/10.1519/00124278-200705000-00026

Girard, O., Mendez-Villanueva, A., \& Bishop, D. (2011). Repeated sprint ability-Part I: Factors contributing to fatigue. Sports Medicine, 41(8), 673-694. https://doi.org/10.2165/11590550-000000000-00000

Glaister, M. (2005). Multiple sprint work: Physiological responses, mechanisms of fatigue and the influence of aerobic fitness. Sports Medicine, 35(9). 757-777. https://doi.org/10.2165/00007256-200535090-00003

Hazir, T., Aşçı, A., Ozkara, A., Açıkada, C., Tinazci, C., Cinemre, A., \& Mavili, S. (2002). The physical and biomotor profiles of super league soccer players in Turkey: Comparing according to the positions. $7^{\text {th }}$ International Sport Science Congress, Antalya, 59.

Helgerud, J., Engen, CL., Wisloff, U., \& Hoff, J. (2001). Aerobik endurance training improves soccer performance. Medicine and Science in Sports and Exercise, 33(11), 1925-1931. https://doi.org/10.1097/00005768-200111000-00019

Impellizzeri, FM., Rampinini, E., Castagna, C., Bishop, D., Ferrari Bravo, D., Tibaudi, A., \& Wisloff, U. (2008). Validity of a repeated sprint test for football. International Journal of Sports Medicine, 29(11), 899-905. https://doi.org/10.1055/s-2008-1038491

İnal, NA. (2004). Futbol'da eğitim ögrretim. Nobel Yayın Dağıtım, Ankara.

Krustrup, P., Mohr, M., Nybo, L., Jensen, MJ., Nielsen, JJ., \& Bangsbo, J. (2006). The Yo-Yo IR2 test: Physiological response, reliability, and application to elite soccer. Medicine and Science in Sports and Exercise, 38(9), 1666-1673. https://doi.org/10.1249/01.mss.0000227538.20799.08

Lago-Penas, C., Casais, L., Dellal, A., Rey, E., \& Dominguez, E. (2011). Anthropometric and physiological characteristics of young soccer players according to their playing positions: Relevance for competition success. Journal of Strength and Conditioning Research, 25(12), 3358-3367. https://doi.org/10.1519/JSC.0b013e318216305d

Malina, RM., Cumming, SP., Kontos, AP., Eisenmann, JC., Ribeiro, B., \& Aroso, J. (2005). Maturity-associated variation in sport-specific skills of youth soccer players aged 13-15 years. Journal of Sports Science, 23(5), 515-522. https://doi.org/10.1080/02640410410001729928

Malina, RM., Eisenmann, JC., Cumming, SP., Ribeiro, B., \& Aroso, J. (2004). Maturity-associated variation in the growth and functional capacities of youth football (soccer) players 13-15 years. European Journal of Applied Physiology, 91(5-6), 555-562. https://doi.org/10.1007/s00421-003-0995-z

Mohr, M., Krustrup, P., \& Bangsbo, J. (2003). Match performance of high standart soccer players with special reference to development of fatigue. Journal of Sports Sciences, 21(7), 519-528. https://doi.org/10.1080/0264041031000071182

Mujika, I., Spencer, M., Santisteban, J., Goiriena, JJ., \& Bishop, D. (2009). Age-related differences in repeated-sprint ability in highly trained youth football players, Journal of Sports Sciences, 27(14), 1581-1590. https://doi.org/10.1080/02640410903350281

Oliver, JL. (2009). Is a fatigue index a worthwhile measure of repeated sprint ability. Journal of Science and Medicine in Sport, 12(1), 20-23. https://doi.org/10.1016/j.jsams.2007.10.010

Özdemir, FM., Yılmaz, A., \& Kin-İşler, A. (2014). Age related differences in repeated sprint performance in young football Players. Hacettepe Journal of Sport Sciences, 25(1), 1-10.

Rampinini, E., Bishop, D., Marcora, SM., Ferrari Bravo, D., Sassi, R., \& Impellizzeri, FM. (2007). Validity of simple field tests as indicators of match-related physical performance in top-level professional soccer players. International Journal of Sports Medicine, 28(3), 228-235. https://doi.org/10.1055/s-2006-924340

Rampinini, E., Sassi, A., Morelli, A., Mazzoni, S., Franchini, M., \& Coutts, A. J. (2009). Repeated-sprint ability in professional and amateur soccer players. Applied Physiology, Nutrition and Metabolism, 34(6), 1048-1054. https://doi.org/10.1139/H09-111

Ratel, S., Duche, P., \& Williams, CA. (2006). Muscle fatigue during high-intensity exercise in children. Sports Medicine, 36(12), 1031-1065. https://doi.org/10.2165/00007256-200636120-00004 
Reilly T., \& Thomas V. (1976). A motion analysis of work-rate in different positional roles in professional football match-play. Journal of Human Movement Studies, 2, 87-97.

Reilly, T., \& Wells, C. (1999). Influence of playing position on fitness and performance measures in female soccer players. Communications to the Fourth World Congress of Science and Football, Journal of Sports Sciences, 17, 820-821.

Reilly, T., Bangsbo, J., \& Franks, A. (2000). Anthropometric and physiological predispositions for elite soccer. Journal of Sport Sciences, 18(9), 669-683. https://doi.org/10.1080/02640410050120050

Silvestre, R., West, C., Maresh, CM., \& Kraemer, WJ. (2006). Body composition and physical performance in men's soccer: A study of a national collegiate athletic association division I team. Journal of Strength and Conditioning Research, 20(1), 177-183. https://doi.org/10.1519/R-17715.1

Spencer, M., Bishop, D., Dawson, B., \& Goodman, C. (2005). Physiological and metabolic responses of repeated sprint activities: Specific to field-based team sports. Sports Medicine, 35(12), 1025-1044. https://doi.org/10.2165/00007256-200535120-00003

Spencer, M., Fitzsimons, M., Dawson, B., Bishop, D., \& Goodman, C. (2006). Reliability of a repeated-sprint test for field-hockey. Journal of Science and Medicine in Sport, 9(1-2), 181-184. https://doi.org/10.1016/j.jsams.2005.05.001

Spencer, M., Lawrence, S., Rechichi, C., Bishop, D., Dawson, B., \& Goodman, C. (2004). Time-motion analysis of elite field-hokey: Special reference to repeated-spirnt activity. Journal of Sports Sciences, 22(9), 843-850. https://doi.org/10.1080/02640410410001716715

Sporis, G., Milanovic, Z., Trajkovic, N., Erceg, M., \& Novak, D. (2012). Relationship between functional capacities and performance parameters in soccer. Journal of Sports Medicine and Doping Studies, 1-5.

Stolen, T., Chamari, K., Castagna, C., \& Wisloff, U. (2005). Physiology of soccer. Sport Medicine, 35(6), 501-536. https://doi.org/10.2165/00007256-200535060-00004

Taşkın, H. (2008). Evaluating sprinting ability, density of acceleration, and speed dribbling ability of professional soccer playing with respect to their positions. Journal of Strength and Conditioning Research, 22(5), 1481-1486. https://doi.org/10.1519/JSC.0b013e318181fd90

Whall, R. (2001). Conditioning the goalkeepers: A specific approach. Insight: the FA Coaches Association Journal, 4 , 23-25.

Wong, DP., Chan, GS., \& Smith, AW. (2012). Repeated sprint and change of direction abilities in physically active individuals and soccer players: Training and testing implications. Journal of Strength and Conditioning Research, 26(9), 2324-2330. https://doi.org/10.1519/JSC.0b013e31823daeab

Wong, PL., Chamari, K., Dellal, A., \& Wisloff, U. (2009). Relationship between anthropometric and physiological characteristics in youth soccer players. Journal of Strength and Conditioning Research, 23(4), 1204-1210. https://doi.org/10.1519/JSC.0b013e31819f1e52 